\title{
Aeromagnetic study of peninsular India
}

\author{
P HARIKUmar, Mita RAJARAM* and T S BALAKRISHNAN \\ Indian Institute of Geomagnetism, Colaba, Mumbai 400005, India. \\ e-mail: mita@iig.iigm.res.in
}

\begin{abstract}
The degree sheet Aeromagnetic maps up to $17^{\circ} \mathrm{N}$, acquired from the Geological Survey of India, have been manually redigitised at 6 minute intervals to study the long wavelength anomalies over peninsular India. These data have been collected at different survey altitude, epochs, flight line directions, etc. Great care has been taken to correct the total field map and remove the contribution due to the core field and prepare an accurate crustal anomaly map. For the first time, a regional map, depicting the NW-SE structural features north of the orthopyroxene isograd with the essentially $\mathrm{E}-\mathrm{W}$ features to the south of it and revealing several well known structures, is presented. The analytical signal is calculated to delineate the source fields of these anomalies. It dramatically maps the charnockites and is able to delineate the orthopyroxene isograd. In the Dharwar region the magnetic signatures are associated with the intrusives/ iron ore bodies. Thus, we find that the source rocks of the aeromagnetic anomalies are the host province of charnockites in the SGT and the intrusives/iron ore bodies in the Dharwar belt. Gravity residuals are calculated and a tectonic map of the region is presented from the combined geopotential data.
\end{abstract}

\section{Introduction}

An aeromagnetic survey is the most economical method of undertaking a geophysical reconnaissance of any relatively unexplored or inaccessible region. It provides data on a broad scale of structural trends, the position of faults, and the distribution of shallow or deep crystalline basement as well as the occurrence of volcanic rocks within a sedimentary basin. 'A National Program' of aeromagnetic survey was organized by the Geological Survey of India (GSI) to cover the entire country by systematic aeromagnetic surveys with the professional and technical assistance of the National Remote Sensing Agency (NRSA) and this continued for a period of fifteen years starting from 1980. The survey results were published in the form of total intensity contour maps in degree sheet format, but were not corrected for variations due to the main field of the Earth. Some regions have been surveyed under other projects such as Operation Hard Rock for mineral exploration and detailed maps are available for these projects. However, degree sheet maps are not available over this region. Also, no new maps were made wher- ever National Geophysical Research Institute and Atomic Minerals Division had conducted multi sensor airborne surveys. The altitude of the surveys varied depending on requirement and topography.

Reddy et al (1988) have published valuable results up to 12 degrees north using the collected aeromagnetic data and under Project Vasundhara (1994) GSI have utilized the aeromagnetic data up to $14^{\circ} \mathrm{N}$ for their interpretation and only published the trends of the anomalies. Bahulayen (1997) has published a map of the region up to $14^{\circ} \mathrm{N}$ incorporating corrections for the main geomagnetic field. All these papers have utilised the original data that are very closely spaced and these have very effectively brought out the finer structures but many of the long range correlations have been lost out in the details. As part of a DST project related to the understanding of the complexities of the deep crust, we have acquired the degree sheet total intensity aeromagnetic maps up to $17^{\circ} \mathrm{N}$. The mosaic of aeromagnetic maps acquired have different altitudes, epoch of survey, line spacing and line direction. As the main geomagnetic field is known to undergo secular variations and change with altitude, the

Keywords. Aeromagnetic; Southern Granulite Terrain; IGRF; analytical signal; metamorphism. 
preparation of an accurate magnetic field anomaly map over the peninsular region is a non-trivial task. At the same time the preparation of a good and accurate aeromagnetic anomaly map is extremely crucial for the proper identification and understanding of the magnetic sources. It is our endeavor in this paper to first prepare an accurate anomaly map of the Indian peninsula up to $17^{\circ} \mathrm{N}$, with the purpose of understanding the deep crust and the tectonic features of the region. The main aim is to identify and isolate the sources and understand the cause of the aeromagnetic anomalies. In what follows we first briefly describe the geology and tectonics of the region under investigation; next we delve on the preparation of an accurate aeromagnetic anomaly map and then go on to transform this map and couple it with gravity to describe the tectonics of the region.

\section{Geology and tectonics}

Figure 1 redrawn from GSI (1993) and Drury et al (1984) depicts the general geology and broad tectonics of the peninsular India up to $17^{\circ}$ North. The study area of peninsular shield constitutes three major tectonic elements, i.e. Karnataka (Dharwar) craton, Eastern Ghat Mobile belt and the South Indian granulite province. Each of these can be divided further. The

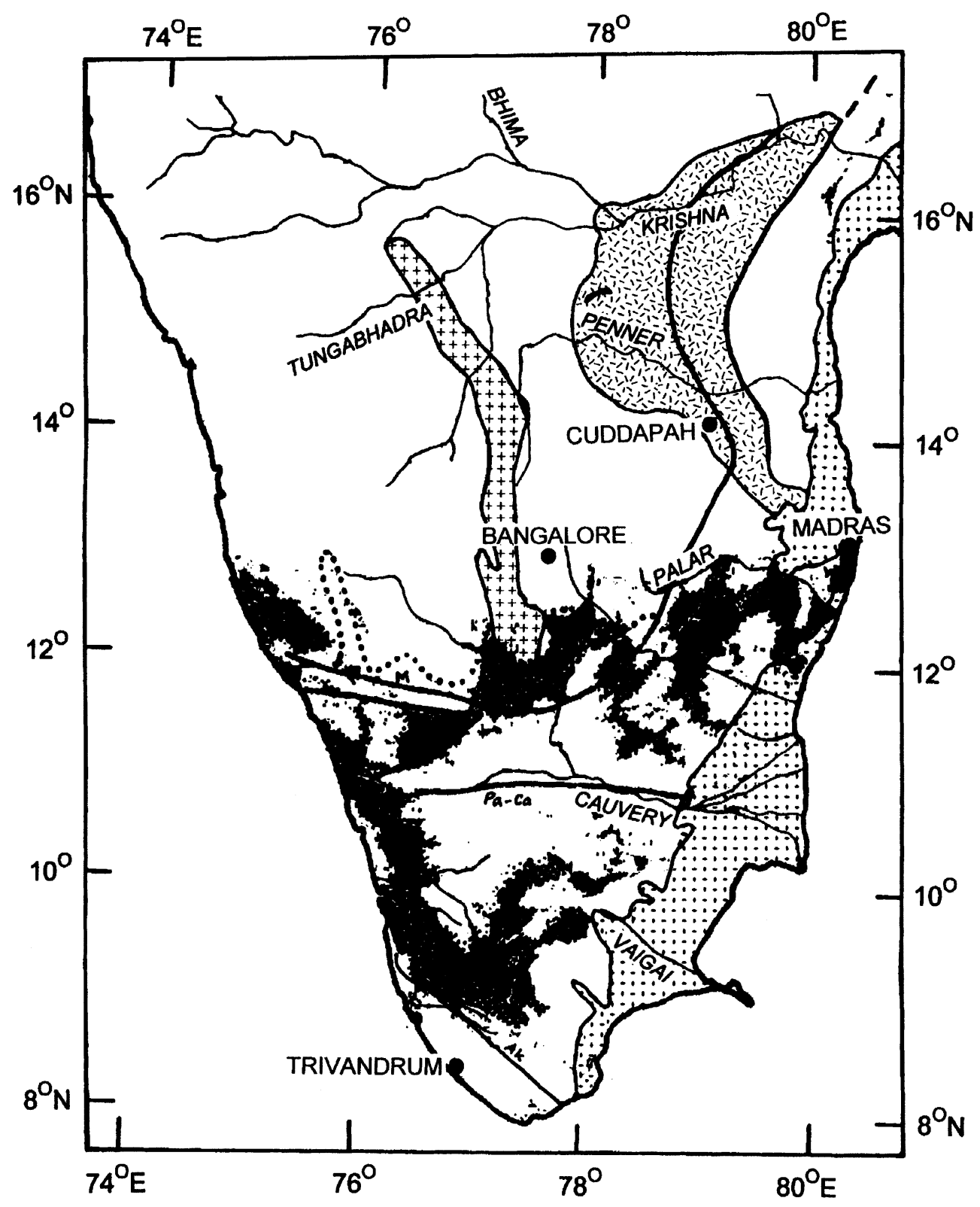

Figure 1. General geology and tectonics of peninsular India (redrawn from Drury et al (1984) and GSI (1993)). Thick bold lines indicate tectonic elements; M - Moyar; Pa-Ca - Palghat Cauvery shear; Ak - Achankovil shear; speckled - Cuddapah basin; dotted lines - orthopyroxene isograd. The important rivers are shown. +++ Closepet granites; dots for sedimantary basin separated from crystallines; dark patches represent the mapped charnockites. 
Karnataka craton, bounded in the north by Deccan lava flows has three major tectonic elements. The Dharwar schist belt (larger schist belts, >3.0 Ga) forms the western block; the Kolar type schist belt (auriferous, $\sim 2.5 \mathrm{Ga}$ ) forms the eastern block and the $\mathrm{N}$-S trending closepet granite $(\sim 2.5 \mathrm{Ga})$, demarcates the boundary of these blocks (Radhakrishna and Vaidyanadhan 1997). The most characteristic feature of the Archean cover sequences of the Dharwar craton is their arcuate N-S trend with convexity towards the east. Kimberlite pipes are reported at this boundary in Wajrakarur-Lattavaram kimberlite belt. The Dharwar craton is separated from the Eastern Ghats belt by the major thrust along the eastern margin of the Cuddapah basin. To the south of this is the MoyarBhavani, Palghat-Cauvery shear systems (Ramakrishnan 1993), a transition zone marked by gradation in metamorphism from gneisses to charnockites which separates the Dharwar craton from the granulite terrain in the south. The gravity anomalies across this region are smoothly varying.

The Southern Granulite Terrain (SGT) is further divided into three major blocks. The Northern Granulite block occupies the area between the Dharwar craton and the Palghat-Cauvery shear zone and defines the transition between the low- and highgrade terrains $(\sim 2.5 \mathrm{Ga})$. The southern granulite block is the region between two major shear zones viz., Palghat-Cauvery and Achankovil (age 0.5-0.7 Ga). It includes most of the highlands whose maximum elevation is $2600 \mathrm{~m}$. To the south of Achankovil shear zone is the Kerala Khondalite Block, a seat of metasedimentary granulites (2100-2830 Ma).

The known faults and shears of the peninsular shield closely follows the pattern of major rivers. The MoyarBhavani, Vaigai and Cauvery shears are typical examples from the south. Towards north, rivers Krishna, Tunga-Bhadra, Palar, Bhima etc are associated with known shears. In addition, there are major parallel N-S shears in the western block of Karnataka craton, like the Chitradurga boundary fault between the western and eastern blocks. The Panjim fault which runs in a NE-SW direction extends in to the Arabian Sea.

Metamorphism affects the nature of $\mathrm{Fe}$ compounds in rocks and thus affects susceptibility. Shive et al (1992), have discussed at length, the magnetic properties of lower continental crust. They have also discussed the effect of metamorphism on magnetic susceptibility. Mayhew, Wasilewski and Johnson (1991) illustrated that, for a basic rock carried up through metamorphic grades, the transition to greenschist grade destroys original magnetic materials, iron being tied up on nonmagnetic silicate minerals or weakly magnetic spinels. Amphibolite-grade rocks are rather unpredictable, containing highly variable amounts of magnetite, depending on the specific petrogenetic conditions under which they are formed.
Magnetizations of these rocks vary over orders of magnitude. They are much more weakly magnetic than the same rocks in the granulite facies. As the granulite grade is reached, iron is released from nonmagnetic minerals to form grains of nearly pure magnetite, producing strongly magnetic rocks, especially those having more mafic compositions. Thus, the granulite grade levels of the deep crust are very likely the most important regionally extensive zones of enhanced magnetization. At eclogite grade, iron again enters silicate minerals such as garnet, and magnetization falls to low levels. Granulitic or charnockitic rocks in the southern granulitic terrain show a calcalkaline chemical composition overlapping that of the peninsular gneiss (Patwardhan 1999); this would not give rise to large gravity anomalies but it is their mineralogical content that would separate them in terms of their magnetic signatures especially since susceptibility ranges can be very large. It is in this light that the magnetic signatures of the aeromagnetic data will help to map the grade of metamorphism below the surface geology.

\section{Aeromagnetic anomaly map preparation}

Aeromagnetic surveys over the peninsular shield were conducted from 1980 to 1989. In the eastern part and parts of northern Karnataka the data are collected at an altitude of $5000 \mathrm{ft}(1515 \mathrm{~m})$. In the rest of the western part of the peninsula, the data are collected at $7000 \mathrm{ft}(2121 \mathrm{~m})$ except in a narrow region in the centre, where the flight altitude is $9500 \mathrm{ft}(2850 \mathrm{~m})$, to clear high topography. The flight lines in the region where the flight altitude is $7000 \mathrm{ft}$ are $\mathrm{N} 25^{\circ} \mathrm{E}-\mathrm{S} 25^{\circ} \mathrm{W}$ and for the rest of the region, the flight lines are $\mathrm{N}-\mathrm{S}$. Hence, the whole area can be demarcated in to different blocks by virtue of these parameters (inset of figure 2). The line spacing for all these blocks was maintained at $4 \mathrm{~km}$, except for the drape survey over Cuddapah basin covered under Operation Hard Rock (OHR) where, the line spacing varied from 500 meters to $1 \mathrm{~km}$. It thus becomes inevitable to reduce the data to a common barometric altitude to obtain an overall idea of the magnetic response of the geological terrain in general. The catalogue published by Geological Survey of India (1995) includes details about the aeromagnetic data. There however exists a data gap, as degree sheets were not available over the Cuddapah basin. We have incorporated ground magnetic data over this basin, collected at $10 \mathrm{~km}$ interval by Indian Institute of Geomagnetism (IIG) to fill this gap in the aeromagnetic data. Rajaram et al (2000) noted that most of the long wavelength features at aeromagnetic height, redigitized at 6 minute intervals, are also evident on ground data collected at $10 \mathrm{~km}$ interval. The data over Salem in Tamil Nadu are not available due to lack of defence clearance. 


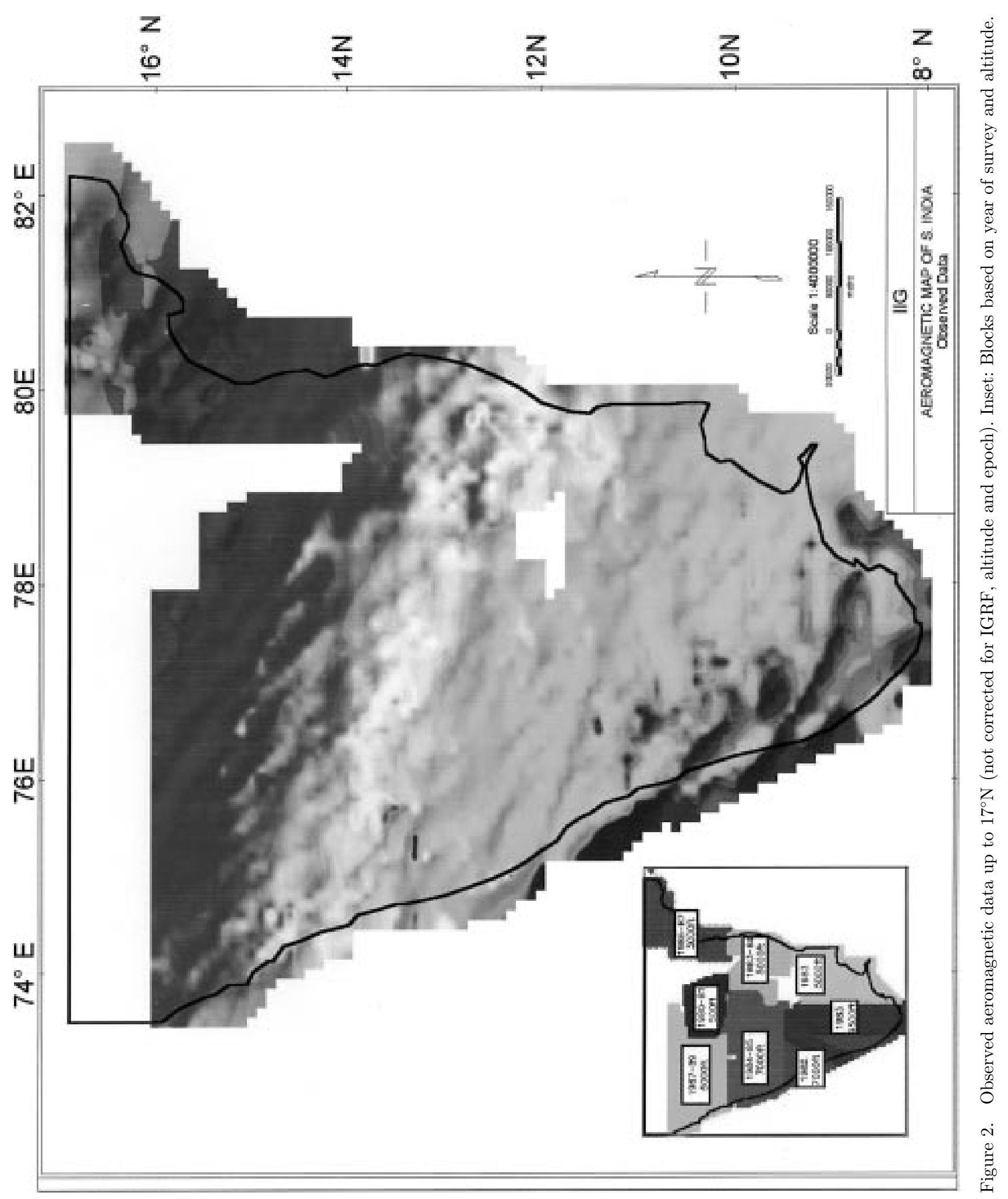


Only contoured maps were available from GSI. In order to apply any corrections to the observed data and for any kind of analysis, it is necessary to have digital data. These degree maps had therefore, to be re-digitized. The data grid spacing has a crucial effect on the nature of the map prepared. Maps made with small grid spacing can delineate finer details, while those with larger grid spacing represent larger wavelengths corresponding to broader, deeper features. The primary objective of the current project is to understand the complexities of the deep crust without getting bogged down by the surface details. Therefore, we have re-digitized the available magnetic total intensity maps manually at 6 minute intervals. A plot of this raw data is given in figure 2 . It is obvious that this map is dominated by the core field variations ranging from $39,000 \mathrm{nT}$ (blue) in the southwest to $42,000 \mathrm{nT}$ (magenta) in the north east of the region with obvious NW-SE trends. These digitized data were then reprocessed in the following manner to isolate the aeromagnetic anomaly due to crustal sources.

The International Geomagnetic Reference field (IGRF) is a spherical harmonic expansion of the geomagnetic field (Langel 1990) and it describes the theoretical undisturbed magnetic field at any point on the earth's surface caused by the main core field. The spherical harmonic coefficients of the IGRF model are calculated from global magnetic observations based on observatory, surveys, marine and satellite data. The internal field undergoes secular variation over a period of time and the IGRF models are revised every five years to incorporate these changes with each model being able to interpolate the data for the time periods between two main IGRF models. For the present study the main core field is represented by harmonics up to degree and order 10 . The observed aeromagnetic data for each block shown in the inset of figure 2, is corrected using the appropriate IGRF models; thus we had to use the IGRF models 1980 and 1985, with the model being interpolated to the appropriate date and the altitude of observation.

The IGRF removed data in the different blocks are at different elevations. The maximum amount of data is collected at $7000 \mathrm{ft}$, and therefore different blocks are continued to the same elevation of $7000 \mathrm{ft}$ above mean sea level. The data sets when continued to the same elevations over adjacent areas are found to mismatch along the area boundaries. This discrepancy can be attributed to irregularities in flight line spacing and direction, combined with changes in elevation and epoch of surveys (Bhattacharyya et al 1979). The discrepancy is more predominant between blocks deviant in flight line directions. We have only one common data point between adjacent blocks along latitude and/or longitude. An algorithm by Johnson et al (1999) was used to merge different blocks after continuing each one to the same datum of $7000 \mathrm{ft}$. above m.s.l. (Geosoft 1999). The colour-shaded image of the aeromagnetic crustal anomaly map, thus prepared is presented in figure 3 . The warm red colours represent highs and the cool blue colours represent lows.

The visual interpretation of the aeromagnetic anomaly map yields many interesting results. A very striking feature of the map is the fact that it is able to bring out regional characteristics of the peninsula very distinctively without being distorted by the very short wavelength surface features. The map shows very clearly the tectonic elements of the region with a change in gradients and trend. Looking from the north, the predominant trends change from NW-SE to $\mathrm{E}-\mathrm{W}$ at the orthopyroxene isograd. A striking contrast in gradients across the Moyar-Bhavani shear system is indicative of a change in the magnetic sources. The region between the line of change of facies and the Palghat-Cauvery shear zone exhibits eastwest trending alternate highs and lows. A very striking feature evident on the map is a set of two NW-SE lineation both extending from north of Sandur. One of them cuts through the Cuddapah basin to the south of Madras. This lineament probably has some major significance, because kimberlite pipes are known to exist in the region between these and the NE-SW trending cross faults near Wajrakarur; we call this NW-SE lineament the Wajrakarur (Wk) lineament. Sreedhar Murthy (1999) noted a NW-SE linear feature from north of Mumbai to Chennai, through Cuddapah basin based on his shaded relief map of free-air gravity anomaly. Since this linear feature is evident in both gravity and magnetic picture, it shall possibly have the same source and is likely to have major implications. The other NW-SE linear is close to the north eastern edge of the closepet granite and we call it the Sandur (Sa) lineament. Also evident on this map is the extension of the NW-SE trending Bhima (Bh) Shear and the Dindi (D) fault. Cutting across the Dharwar are three cross trends; northern most trend is related to the Tungabhadra $(\mathrm{Tu})$ river, the next possibly joins with the Kolhapur-Kurnool (K-K) lineament and together with the $\mathrm{Wk}$ fault is responsible for the crescent shape of the Cuddapah basin. The third cross feature we call as Mangalore-Cuddapah (M-C) lineament also runs across the Dharwars. The west coast faults (a system of faults) running parallel to the coast line is dissected. The exact position of all the faults and lineaments discussed are shown in figure 6 .

Signatures associated with major rivers like Vaigai (V), Cauvery, Palar (P), Pennar, Krishna, etc. are visible on the map. Also evident is the Chitradurga boundary fault $(\mathrm{Ch})$ that separates the eastern and western blocks of Dharwars. It appears that the susceptibility contrast between granites and gneisses of Dharwars are not very large. Another striking aspect is the evidence of the boundary between sedimentary and crystallines on the eastern part of the map. The various basins such as Cauvery, Krishna-Godavary, Palar and Cuddapah are characterized essentially by a low in magnetic values. 


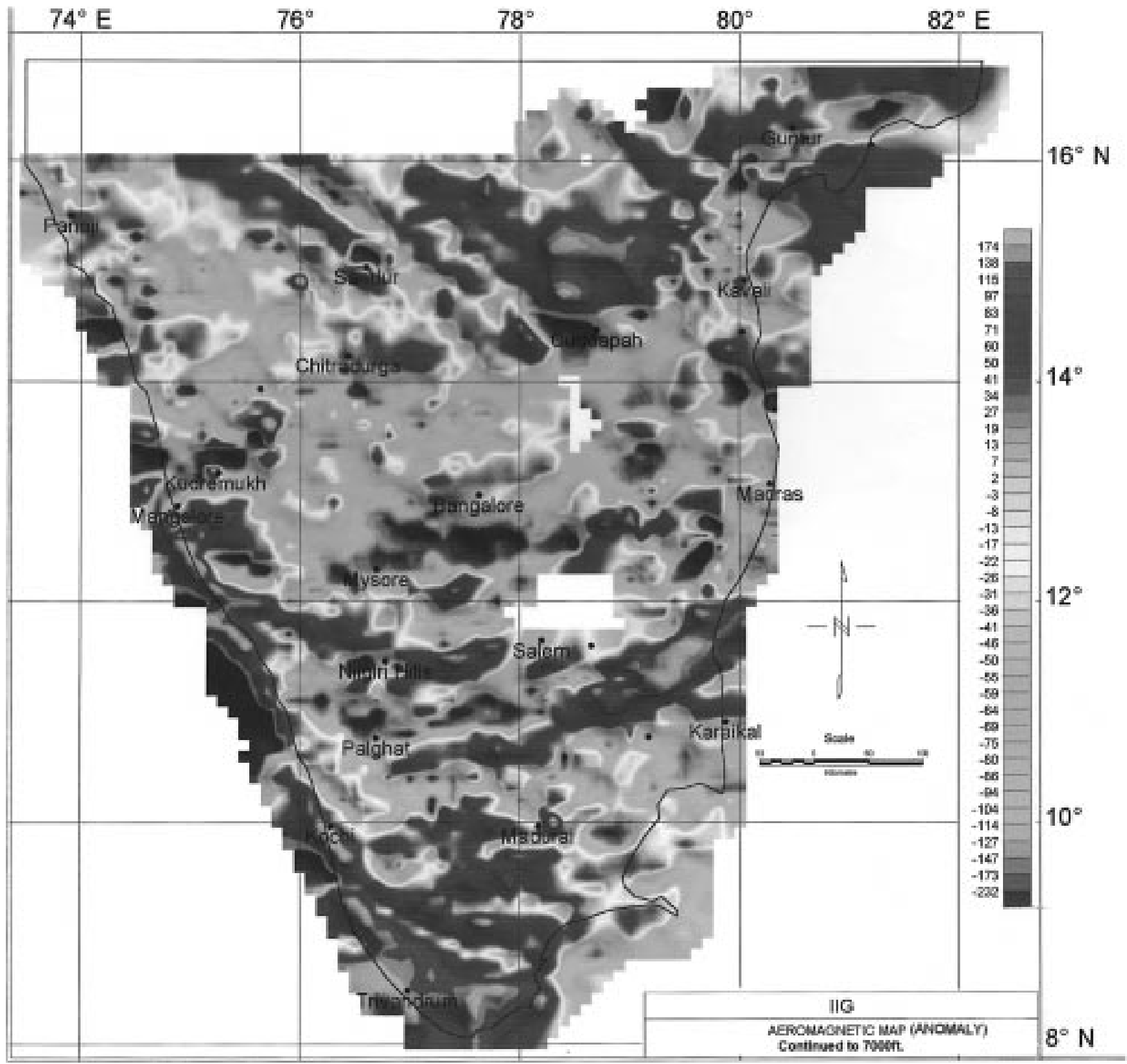

Figure 3. Crustal aeromagnetic anomaly map over peninsular India after corrections.

Achankovil (Ak) shear is very clearly visible in the magnetic picture. A magnetic high can be traced from the western boundary fault to the Mandapam ridge in the East. It may be noted that the drilling studies of ONGC yielded a basaltic basement in Mandapam (Kumar 1983). The dolerite dyke swarms near Kottayam oriented in NW-SE direction over a $100 \mathrm{~km} \times 25 \mathrm{~km}$ zone in central Kerala may be related to this system of intrusives. The dyke emplacement is attributed to the time of the west coast faulting. The khondalites south of Ak-Tenmalai shears are showing a prominent magnetic high extending to offshore but with very low gradients. The contours related to the Palghat-Cauvery shear are seen to extend offshore.

\section{Tectonic map of peninsular shield}

To be able to prepare a tectonic map of peninsular India from geopotential data, we need to define the source field as seen in both the magnetic and gravity data. The vector nature of the magnetic data increases the complexity of the anomalies and makes the interpretation very difficult; therefore one often resorts to reduction to the pole for simplifying the interpretation. At low latitudes, this process is not straight forward. Analytical signal is a practical alternative to reduction to the pole and aids in the delineation of the source body in the aeromagnetic data. For gravity data, residuals can directly be used to define the source. The tectonic elements can be delineated from the 


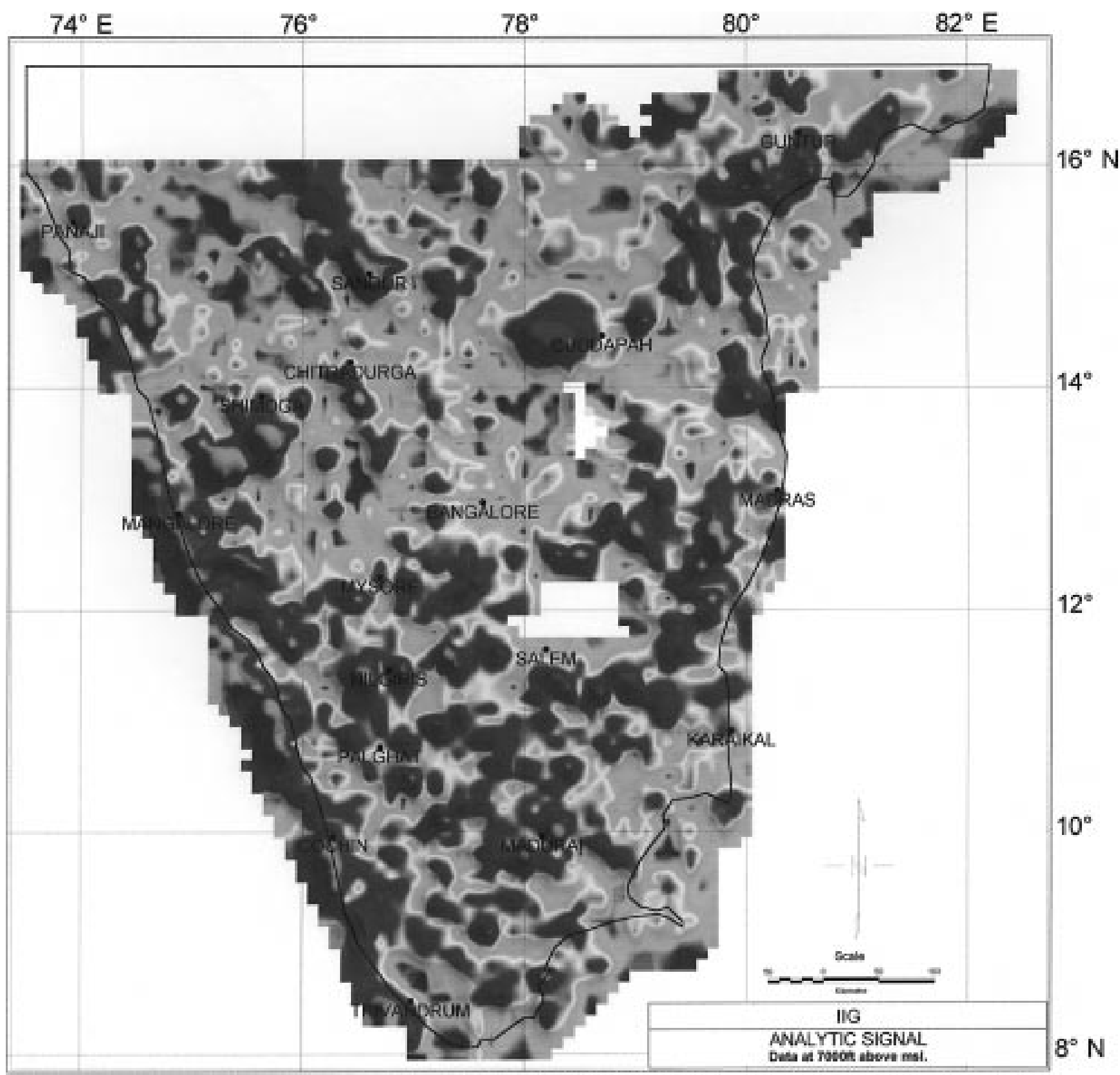

Figure 4. Analytical signal of aeromagnetic anomaly over peninsular India.

gravity residuals by picking the lines of maximum gradients. The gravity anomalies directly overlie the structures unlike the magnetic anomalies which are dependent on the inclination of the inducing field and being dipolar in nature, need not overlie the body. In low latitude regions like India, interpretation of magnetic anomalies becomes very difficult. Therefore, to be able to identify the magnetic sources (body) we calculate the analytical signal.

\subsection{Analytical signal}

The absolute value of the analytic signal is defined as the square root of the squared sum of the vertical and the two horizontal derivatives of the magnetic field. This signal exhibits maxima over magnetization contrasts, independent of the ambient magnetic field and source magnetization directions. Locations of these maxima thus determine the outlines of magnetic sources (Roest et al 1992; MacLeod et al 2000). The analytical signal of the total magnetic field reduces the magnetic data to anomalies whose maxima mark the edges of the magnetised bodies. At low latitudes, an extensive source body will have stronger analytical signal at their north and south edges. Figure 4 depicts the analytical signal of the aeromagnetic anomalies over the peninsula. A striking feature of the analytical signal map is that the 
Dharwars are devoid of much magnetization contrasts except for the iron ore deposits of Sandur, Goa, Kudremukh and the intrusives in Cuddapah. Quite surprisingly the signatures of the Closepet granites show up clearly in this map as a series of intrusives, though it is not quite evident directly in the aeromagnetic anomaly map. The presence of abundant magnetite in plutonic rocks, including granitic rocks, is taken as an indicator of high oxygen fugacity (Patwardhan 1999). The Eastern Ghats are characterized by a zone of maxima in an arcuate shape with convexity towards west. It is very interesting to note that the M-C lineament restricts most of the highs to lie to its north, in the Cuddapah region. At $13^{\circ} \mathrm{N}$ parallel, the trends of the maxima align itself along the E-W direction parallel to the orthopyroxene isograd. In fact we can map the orthopyroxene isograd from this map (shown by dots in figure 6 ). The trends turn to an essentially NW-SE direction below the Pa-Ca shear system. The zone between Moyar Bhavani-Salem-Attur faults and the Achankovil shear zone is characterized by many maxima. The line of separation of the crystallines and sediments can be clearly discerned from this map. Also surprisingly no signatures of the khondalite belts are evident in this picture though they show clear highs in the aeromagnetic anomaly map. The west coast fault is seen as a system of faults, intersected by various cross faults.

A very important aspect of figure 4 is that the analytical signal peaks within the Dharwar region are of the type that represent intrusives/localised iron ore bodies while south of the orthopyroxene isograd there are several peaks representing extensive sources signifying that the host province is magnetic, they are related to the higher grade of metamorphism of the host province rocks; the granulites, higher grade of metamorphic rocks have susceptibilities greater than gneisses and greenstone, and this is directly evident from the figure. Thus the analytical signal can be used to define the change in grades of metamorphism in the subsurface. A very intriguing result is the fact that south of the Achankovil shear zone the analytical signal does not show any sources though we see a magnetic high in the aeromagnetic map related to the khondalites; it may be noted that there exists low gradients over the khondalites in the aeromagnetic map. The most important result is that the charnockites as evident in the geology map (GSI 1993) match very well with the highs in the analytical signal map. Also all the iron belts mapped in the mineralogical map of Project Vasundhara (1994) overlie the highs of figure 4. This implies that the source rock of the magnetic signatures in the SGT are the charnockites while in the Dharwar greenstone belt they are mainly due to the intrusives/iron ore bodies. The magnetic data can thus play a crucial role in the understanding of the tectonics of the region.

\subsection{Gravity residuals}

To prepare a gravity anomaly map, we have redigitised the Bouguer gravity anomaly map (Balakrishnan 1997), at 10 minute intervals. We calculated the residuals at a given point by subtracting the mean of the gravity values of the nearest four grid points. Figure 5 is a coloured map of the gravity residuals thus prepared. This map also depicts the NW-SE structures in the Dharwar region but is significantly devoid of the large variations that are seen in the SGT region of the aeromagnetic map. In fact in contrast to the aeromagnetic map we find more highs in the Dharwar craton than in the SGT in figure 5. Signatures of closepet granite, Cuddapah basin and the dissected west coast fault are very evident. However, there are no significant or distinct features associated with the charnockites on the gravity residual map. In the eastern block of the SGT there are very prominent ridge and depression structures reflecting essentially the variations in thickness of sedimentary cover. Signatures of Ariyalur basin, Kumbakonam ridge, Pattukotai ridge, Ramnad basin, Mandapam ridge, etc (Balakrishnan 1997) are clearly visible which do not manifest in the magnetic map.

\subsection{Combined gravity magnetic signatures}

In the interpretation of the tectonic structures from the magnetic and gravity data we are guided by Paterson and Reeves (1985) and Wellman (1985):

1. The primary structure of the continent is considered to be a mosaic of crustal blocks of 500 to $1000 \mathrm{~km}$ extent with distinctive history and structure. These primary crustal blocks can be delineated by the predominant trend direction within the block, terminated at a province boundary, as seen in the long wavelength geopotential anomalies. The block containing trends oblique to the boundary is inferred to be older than the boundary and the blocks with trends parallel to be younger.

2. The secondary structure of the continent is the dominant structure within the block and the tertiary structure is considered to be the cross fractures segmenting the secondary structure. These cross features separate the gravity/magnetic trend segments, displace the geologic structures forming the trends. The cross features are moderate to weak features on the main trend with some other trend extending across the province boundary.

Figure 6 is the interpreted tectonic map of peninsular India derived from the aeromagnetic anomaly map (figure 3), its analytical signal (figure 4) and the gravity residuals (figure 5). We have given importance to the magnetic data set and the less prominent signatures are depicted by dashed lines; the lines picked directly from the gravity residuals is shown by light 


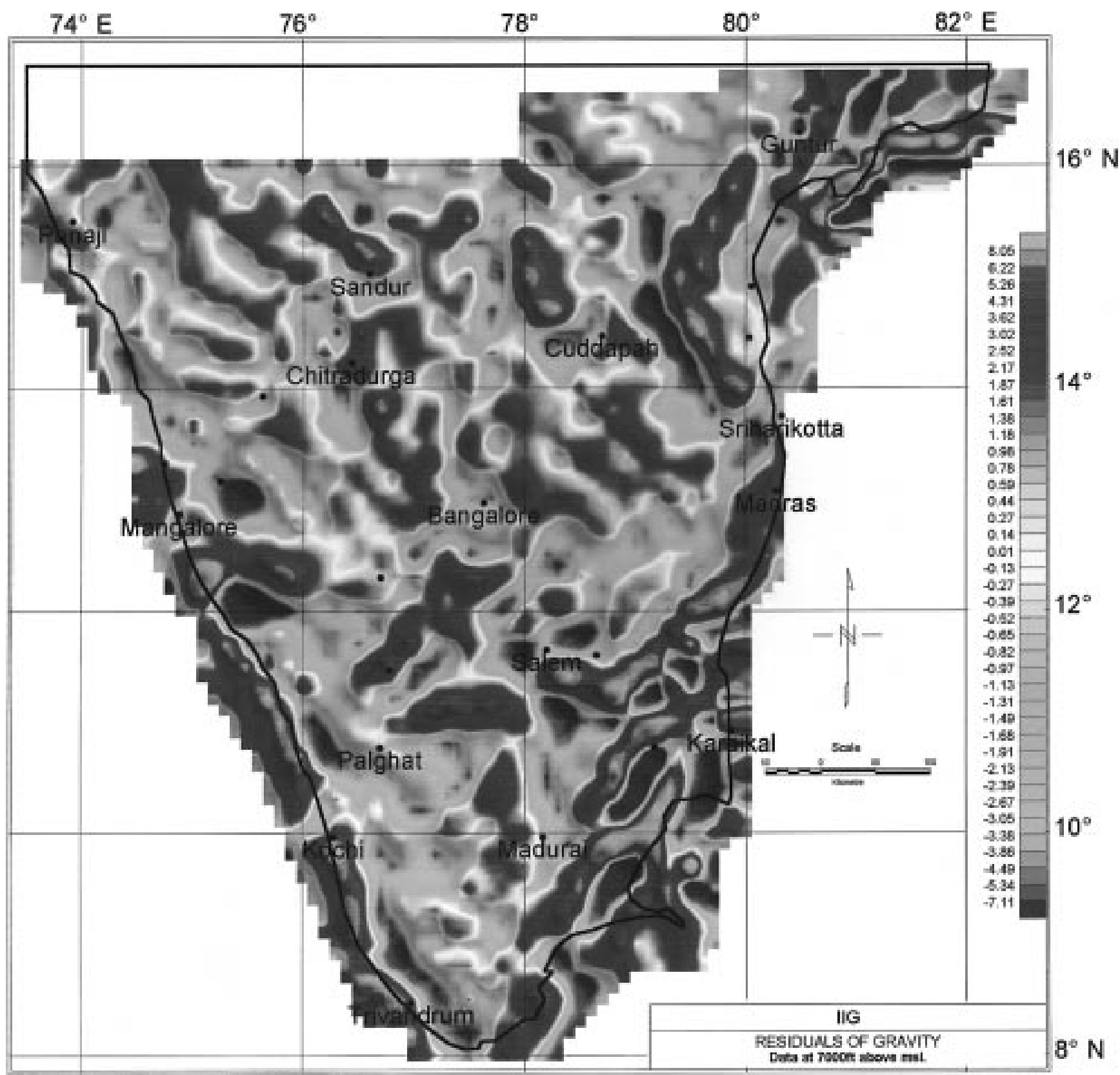

Figure 5. Gravity residuals over peninsular India.

short dashed lines. The tectonic provinces are separated by thrust lines. We can divide the peninsula into three major tectonic blocks: the Dharwar block (with a major NW-SE/NS trends), the eastern ghats (NESW trends) and the Southern Granulite Terrain (E-W trend). From 1 above in this section, we can infer that SGT is younger than the Dharwars and is consistent with known ages. The Dharwar block is essentially free from magnetic signatures except for the known iron ore deposits and the Cuddapah intrusives (from figure 4). Both the western and eastern blocks of the Dharwar separated by the Chitradurga (Ch) boundary fault do not show any significant difference in magnetic signatures and are possibly compositionally similar. A series of NW-SE trending main features are extending across the region. Dindi (D) fault and extension of the Bhima (Bh) fault are clear. Of particular significance is the one going from north right across Cuddapah up to Madras (the Wk lineament) and a feature parallel to it called as Sandur (Sa) lineament. The NE-SW cross feature discussed earlier are also marked. Known kimberlite pipes lie on these cross features. The shear zones comprising of the E-W trending Moyar-Bhavani (M,B) and Palghat Cauvery $(\mathrm{Pa}-\mathrm{Ca})$ shears form the northern part of the SGT. The Achankovil (Ak) shear is also picked up. We believe the highs (figure 4) that are not already mapped on either the charnockites or the iron ore belts in the SGT region, could represent charnockites in the subsurface. 




Figure 6. Interpreted tectonic elements from combined geopotential data. The major lineaments are: Tu: Tungabhadra; K-K: Kolhapur Kurnool; M-C: Mangalore Cuddapah; Bn: Bababudan; Ch: Chitradurga; Sa: Sandur; Wk: Wajrakarur; Bh: Bhima; D: Dindi; M: Moyar; B: Bhavani; Pa-Ca: Palghat Cauvery; P: Palar; Ak: Achankovil; V: Vaigai; W: west coast fault; Cl: Closepet granite. Light short dashed lines are from gravity residuals.

\section{Conclusions}

The preparation of an accurate aeromagnetic anomaly map is very crucial to the study of regional crustal features and the data grid spacing plays a key role to be able to define the regional features without being masked by the short wavelength anomalies. We believe our map depicts the regional characteristics more clearly than the earlier published maps because of the larger data spacing used. A very interesting aspect of the aeromagnetic and gravity anomalies is that the aeromagnetic anomalies show much larger variations than the gravity anomalies due to the larger susceptibility variations than density variations of the crustal rocks. In particular, this has great relevance to the different metamorphic grades of the crustal rocks. However, the interpretation of the magnetic anomalies is more difficult.

From the analytical signal map we infer that the sources of the aeromagnetic anomalies in the Dharwar region are mainly associated with iron ore/intrusives and in the SGT they are the charnockites. The iron 
ore deposits of Kudremukh, Goa, Sandur, Bellary and Salem are clearly visible in the map. Most of the minerals are associated with faults and intrusions. This is an indirect indication of the zones of mineralisation.

Three main tectonic features are inferred from the geopotential data analysis-the Dharwars, Eastern Ghat and SGT. Marine data will help throw light on the extension of the faults and trends into the offshore region. The contact between the Dharwar and the SGT is tectonic in nature and not a mere gradational change of facies. The trends of each of the block are controlled by forces thrusting across the blocks. The cross over point of faults and cross faults could bring up important minerals from the mantle like kimberlites. We believe that the aeromagnetic crustal anomaly map presented in this paper will change the way the earth scientists look at the Indian peninsula; we hope the magnetic data will in future be an integral part of any interpretation related to the crustal studies of the Indian peninsula!

\section{Acknowledgement}

This paper was completed as part of the DST project 'Geophysical study of the Indian sub-continent and its contiguous region for understanding the complexities of the deep crust'. The assistance received from DST is gratefully acknowledged.

\section{References}

Bahuleyan K 1997 Indian magnetic mapping project - an attempt at aeromagnetic assembly for India in the global context; In: Proceedings of the workshop on Airborne Geophysics (ed) Colin V Reeves (Association of Exploration Geophysics India). 77-84

Balakrishnan T S 1997 Major tectonic elements of the Indian subcontinent and contiguous areas: A geophysical review; Geol. Soc. of India Memoir $\mathbf{3 8}$

Bhattacharyya B K, Sweeney R E and Godson R H 1979 Integration of aeromagnetic data acquired at different times with varying elevations and line spacing; Geophysics 44 $742-752$

Drury S A, Harris N B W, Holt R W, Reeves-Smith G J and Wightman R T 1984 Precambrian tectonics and crustal evolution in South India; J. Geol. 92 3-20
Geological Survey of India 1995 Catalogue of aero geophysical maps (Airborne Mineral Surveys and Exploration Wing Bangalore India).

Geosoft 1999 Oasis Montage Data Processing and Analysis (DPA) System for Earth Science Applications (v 4.3) Geosoft Inc.

GSI 1993 Geological Map of India Compiled by A K Dasgupta, A Ghose and K K Chakraborty (Geological Survey of India).

Johnson A, Cheeseman S and Ferris J 1999 Improved compilation of Antarctic Peninsula magnetic data by new interactive grid suturing and blending methods; Annali di Geofisica 42 249-259

Kumar S P 1983 Geology and Hydrocarbon prospects of Krishna Godavari and Cauvery basins; In: Petroliferous basins of India: Petroleum Asia Journal (Dehradun: KDMIPE) 51-65

Langel R A 1990 The main geomagnetic field. In: Geomagnetism (ed) J Jacobs (Academic Press) 250-512

MacLeod Ian N, Jones K and Ting Fan Dai 2000, 3-D Analytic signal in the interpretation of total magnetic field data at low magnetic latitudes (Research papers Geosoft Inc.)

Mayhew M A, Wasilewski P J and Johnson B D 1991 Crustal magnetization and temperature at depth beneath the Yilgarn block Western Australia inferred from Magsat data; Earth Planet. Sci. Lett. 107 515-522

Paterson N R and Reeves V C 1985 Applications of gravity and magnetic surveys; Geophysics 50 2558-2594

Patwardhan A M 1999 The dynamic earth system (NewDelhi: Prentice Hall of India Pvt. Ltd.)

Project Vasundhara 1994 Special Publication AMSE Wing; Geological Survey of India Bangalore.

Radhakrishna B P and Vaidyanadhan R 1997 Geology of Karnataka; Geol. Soc. of India Bangalore.

Rajaram M, Anand S P and Vinit Erram 2000 Crustal magnetic studies over Krishna-Godavari basin in eastern continental margin of India; Gondwana Research 3 385-393

Ramakrishnan M 1993 Tectonic evolution of the granulite terrains of southern India; In: Continental Crust of South India (ed) B P Radhakrishna Geol. Soc. of India Memoir $\mathbf{2 5}$ 45-61

Reddy A G B, Mathew M P, Baldau Singh and Naidu P S 1988 Aeromagnetic evidence of crustal structure in the granulite terrain of Tamil Nadu- Kerala; J. Geol. Soc. India 32 368-381

Roest R W, Verhoef J and Pilkington M 1992 Magnetic interpretation using the 3-D analytic signal; Geophysics $\mathbf{5 7}$ 116-125

Shive P N, Blakely R J, Frost B R and Fountain D M 1992 Magnetic properties of the lower continental crust In: Continental lower crust (ed) D M Fountain, R Arculus and R W Kay (Elsevier Science Publishers) 145-177

Sreedhar Murthy Y 1999 Images of the gravity field of India and their salient features; J. Geol. Soc. India 54 221-235

Wellman P 1985 Block structure of continental crust derived from gravity and magnetic maps, with Australian examples. In: The utility of regional gravity and magnetic anomaly maps (ed) W J Hirze SEG, USA 102-108 